Western Washington University

Western CEDAR

$10-2004$

\title{
Reproductive Measures, Fitness, and Migrating Mennonites: An Evolutionary Analysis
}

Joan C. Stevenson

Western Washington University, joan.stevenson@wwu.edu

Phillip Mark Everson

Western Washington University

Michael Grimes

Western Washington University

Follow this and additional works at: https://cedar.wwu.edu/anthropology_facpubs

Part of the Anthropology Commons

\section{Recommended Citation}

Stevenson, Joan C.; Everson, Phillip Mark; and Grimes, Michael, "Reproductive Measures, Fitness, and Migrating Mennonites: An Evolutionary Analysis" (2004). Anthropology Faculty and Staff Publications. 9.

https://cedar.wwu.edu/anthropology_facpubs/9 
Reproductive Measures, Fitness, and Migrating Mennonites: An Evolutionary Analysis Author(s): JOAN C. STEVENSON, PHILLIP M. EVERSON and MICHAEL GRIMES

Source: Human Biology, Vol. 76, No. 5 (October 2004), pp. 667-687

Published by: Wayne State University Press

Stable URL: http://www.jstor.org/stable/41466272

Accessed: $23 / 10 / 2014$ 14:30

Your use of the JSTOR archive indicates your acceptance of the Terms \& Conditions of Use, available at http://www.jstor.org/page/info/about/policies/terms.jsp

JSTOR is a not-for-profit service that helps scholars, researchers, and students discover, use, and build upon a wide range of content in a trusted digital archive. We use information technology and tools to increase productivity and facilitate new forms of scholarship. For more information about JSTOR, please contact support@ jstor.org. 


\title{
Reproductive Measures, Fitness, and Migrating Mennonites: An Evolutionary Analysis
}

\author{
JOAN C. STEVENSON, ${ }^{1}$ PHILLIP M. EVERSON, ${ }^{1}$ AND MICHAEL GRIMES ${ }^{1}$
}

\begin{abstract}
Given the same reproductive span, more children with shorter interbirth intervals and less parental attention per child should not do as well. There should be intermediate optima in family sizes, but only two studies have demonstrated optima. The goal here is to determine whether the relationship between fitness and fertility is linear and whether this relationship masks underlying variation in reproductive behaviors in a Mennonite congregation that lived in two disease settings, Prussia/Russia vs. Kansas. The relationships between children born and fitness were determined by calculating linear and quadratic regressions for total, Prussia/Russia vs. Kansas, and families with deaths vs. families with no deaths for total, Prussia/Russia, and Kansas. Variation was examined in terms of measures of reproductive success and reproductive span. Comparisons were made by $t$ tests with Bonferroni correction. Regressions demonstrate equally well that the more children women bear, the higher the reproductive success, whether in the harsher disease ecology of rural Prussia/Russia or in less challenging rural Kansas and whether the women experience deaths or not. Prussian/Russian mothers bore significantly more children $(6.5 \pm 0.3)$ than Kansan mothers $(5.6 \pm 0.2)$ over longer reproductive spans but did not significantly increase the number of surviving children ( $4.9 \pm 0.2$ vs. $4.7 \pm 0.2$, respectively). Families experiencing deaths vs. no deaths exhibit significantly longer reproductive spans, reflecting a significantly earlier start at childbearing and a later finish, and produce significantly more children $(5.4 \pm 0.2$ vs. $4.2 \pm 0.2)$. Cox regressions were run, and the most significant covariates to negatively affect survivorship to 15 years were death in the family and length of the previous interbirth intervals. There was variation in families, but perhaps most had adequate nutrition, which may explain the lack of optima in fitness.
\end{abstract}

Reproductive decision making, or the trade-offs that parents make in order to produce children, is complex and always adapted to local contexts (Miller 1994). Flexible estimates based on experience are more adaptive than fixed responses

${ }^{1}$ Department of Anthropology, Western Washington University, Bellingham, WA 98225-9083.

Human Biology, October 2004, v. 76, no. 5, pp. 667-687.

Copyright (C) 2004 Wayne State University Press, Detroit, Michigan 48201-1309

KEYWORDS: BIRTH INTERVAL, OPTIMUM FAMILY SIZE, REGRESSION, REPRODUCTIVE SPAN, REPRODUCTIVE SUCCESS, FITNESS, FERTILITY, MENNONITES, KANSAS, RUSSIA, PRUSSIA. 
when there is greater variance from season to season and more uncertainty overall (Luttbeg and Warner 1999), which is surely characteristic of most of hominid evolution. McNamara (1998) pointed out that it may be difficult to characterize an optimal plastic response when there are variations in environment affecting all population members. It is particularly difficult to produce convincing evidence of optimizing behavior in humans, and Strassmann and Gillespie (2001) argued that there have been only two demonstrations to date.

Given the same reproductive span, more children with shorter interbirth intervals and less parental attention per child should not do as well (Pennington and Harpending 1988). This may be particularly true given challenging settings or contexts in which resources are spread too thinly to support larger families. Pennington and Harpending argued that offspring from larger families should inevitably exhibit higher mortality rates than offspring from smaller families, because birth intervals should necessarily be smaller given roughly the same reproductive span. Shorter birth intervals indicate reduced parental care and can increase the risk of mortality. This is consistent with Lack's (1947) classic study of clutch size in which too many eggs reduced the optimal care per offspring such that optimal fitness was highest for those clutches of intermediate size. However, optimizing behavior in humans seems belied by the fact that, in general, the larger the human family, the higher the fitness (Strassmann and Gillespie 2001).

Blurton Jones and Sibley (1978) successfully applied an optimality analysis to birth intervals in the !Kung and discovered that a woman's "backload," or the energy required to carry a child around while foraging, was an excellent predictor of birth spacing. In addition, Strassmann and Gillespie (2001) examined the number of completed pregnancies versus surviving offspring at 10 years of age in the horticultural Dogon of Mali, West Africa, and found that a maximum reproductive success of $4.1 \pm 0.3$ children was achieved at 10.5 births. They noted that this is only the second time (after Blurton Jones) that optimizing reproductive behavior has been documented in humans. Strassmann and Gillespie suggested that the apparent lack of optimizing reproductive behaviors in human females may be due to the masking effect of a correlation between two phenotypes. In other words, individual women differing in resources may be optimizing their efforts relative to the best health of their offspring (e.g., having varying numbers of children based on the woman's health and access to resources and survivorship of offspring), but when grouped together, the relationship between fitness and fertility is linear. Thus individual women's choices relative to individual circumstances make it difficult to demonstrate larger underlying patterns of optimizing behaviors. Similarly, Blurton Jones (1997) explained the failures of Pennington and Harpending $(1988,1993)$ to replicate his now classic study as a function of the "heterogeneity" among individual mothers and their choices or trade-offs in larger samples of women. Pennington (2001) made a better case for misinterpretation of data by Blurton Jones. The longer the interbirth interval, the relatively fewer children who died because of the shorter risk period associated 
with long interbirth intervals, and thus Blurton Jones's optimum is a methodological artifact.

Our objective here is to determine whether the relationship between fitness and fertility is linear and whether this relationship masks underlying variation in reproductive behaviors in an agricultural Mennonite congregation that lived in two different disease settings: 19th-century Prussia and Russia, and late 19th and early 20th century Kansas. These Mennonites exhibit variation in family size. Some women were having many children, and some were having few or no children, and these patterns changed over time (Stevenson et al. 1994). Patterns in these vital events have been previously described for mortality (Everson et al. 1995; Stevenson and Everson 2000), fertility (Stevenson et al. 1994), and previous and subsequent birth intervals (St. George et al. 2000). Birth intervals were examined only with respect to the maternal depletion and sibling competition hypotheses using a logistic regression hazards model (St. George et al. 2000). Here, we will be examining the relationship between family size and fitness and whether there is variation in the patterns of reproduction; our goal is to determine some of the ways that women maximize reproductive fitness in two disease settings. The intent here is to contrast two different groups of women in two disease settings: women who lost no children versus women who lost at least one child. Child mortality surely influences the patterns of childbearing (minimally shortening the interbirth intervals when women return to cycling sooner), and, depending on local ecology, an optimum family size may be evident in the subgroup losing children.

Pennington and Harpending (1988) formulated a useful model to describe the trade-offs made by parents to maximize fertility given different environmental conditions, noting that different combinations of factors can produce different or similar patterns. Fitness is usually a function of how many offspring are raised to reproductive maturity, and Pennington and Harpending subdivided fitness into (1) length of the reproductive span, (2) the interval between births, (3) the sensitivity of offspring to parental care, and (4) the probability that offspring survive (Pennington and Harpending 1988, p. 305). They noted that parental care can reach a threshold, at which point additional care does not increase the probability that the child will survive, and survivorship of the offspring beyond that parental care "saturation" point reflects largely the care-independent factors that may lead to mortality, such as disease ecology. Reproductive span was not thought to be sufficiently plastic for women to manipulate and was left out of the model, although reproductive span would be a function of cultural preferences for family size relative to typical interbirth intervals and when it was acceptable to start and stop producing children. We include a measure of reproductive span here. Their sophisticated discussion covered much of the dynamics of the interaction of these four fitness variables, and their saturation point concept provides perhaps a better descriptor for a type of optimal behavior for interbirth intervals. 


\section{Sample and Methods}

The Population. The Mennonites represent one segment of the Anabaptist religious movement that emerged during the Reformation (Haury 1981; Urry 1989). Mennonites share ideology and history with the Amish and Hutterites and members of other sects who also believe in adult baptism, preservation of a "simpler" lifestyle, separation from the secular world, and pacifism. Mennonites were first noted in and around the Netherlands and Switzerland and spread to the rest of Europe, particularly Germany. They were severely persecuted, and many settled in West Prussia on the Vistula River delta in the 17th and 18th centuries (then controlled by the Polish-Lithuanian Commonwealth) in an effort to find a safe place to live. They had to pay heavy taxes to avoid military service, but in 1772 they became subjects of Prussia and the military service exemption ceased. They then migrated to the village of Alexanderwohl in New Russia (north of the Black Sea) in 1821, where they stayed until 1874, when the Russian government removed the military exemption and tried to Russianize their schools. They then migrated to Kansas, in the United States. In all locales they were relatively successful farmers who expanded their landholdings, and population increased (Urry 1989). In Prussia and Russia this increase in pacifist Mennonites reduced the men available for military conscription, creating tensions with the government that eventually precipitated migration by one subset of the community.

A small migrating congregation would imply a relatively homogeneous group of families, especially one in which both boys and girls attended Mennonite-controlled schools, but in Russia some families were much more successful than others (Rempel 1974; Urry 1989). Some mothers had large numbers of children, and some had few or none (Stevenson et al. 1994). Russian authorities provided loans and expertise to the Russian Mennonites so that they could experiment in new businesses, including flax production and linen weaving (Rempel 1974; Urry 1989). Their economy diversified as new crop methods were tried and new breeds of cattle, sheep, and horses resistant to local conditions were introduced. Some Mennonites became well-to-do so that a few families controlled most of the land. These differences in access to resources might partially account for differences in family sizes and associated reproductive behaviors because there could be differences in the economic importance of children. Tensions between land-owning and landless families finally resulted in a settlement in 1866 benefiting the poor. When Russian administrators threatened Mennonite autonomy, the most conservative Mennonites moved again.

Data. King Frederick William II commanded that all Prussian churches chronicle the vital statistics of their members, and thus the registry for the congregation was begun in 1784 (Duerksen 1955; Mennonite Immigrant Historical Foundation 1980). In 1821 most of the congregation moved to Russia and changed the name of the church to Alexanderwohl-and they continued record keeping (Mennonite Immigrant Historical Foundation 1987). Post-1874 records, 
representing their stay in Kansas, were retrieved from Bethel College Archives in North Newton, Kansas. This record of vital events for the members of this congregation and their children include dates of birth, baptism, marriage, and death. The most significant lacunae are the dates of death. Individuals who did not migrate or who changed congregations are not recorded. For many of these individuals the registration of baptism or marriage indicates that they survived childhood.

Underreporting of births, especially those for which the neonate or infant died, cannot be ruled out. However, there are several reasons to rule out systematic underreporting. First, Mennonites settled densely, and frequent social interactions meant that births and deaths were publicly known. Second, neonates or infants who died were registered for all women of effective fecundability, that is, married women. These infants were named and registered in reasonably high frequencies. Third, there is no ethnographic evidence that supports a practice of ignoring such deaths. Fourth, longer intervals between births (indicative of underreporting) are not restricted to specific families.

The sexes were not separated for most analyses because of small frequencies. There is little ethnographic evidence that boys and girls were treated differently as small children. Both boys and girls were educated (Ens 1989), and both had equal rights to material wealth at the death of a parent (Urry 1989).

Analysis. For each individual there are vital dates (birth, baptism, marriage, and death) and the dates that link each to the mother and siblings. See Stevenson et al. (1994) for a description of the data as numbers of persons by period, sex, and vital dates. Life spans, mother's ages at the births of children, children's positions in their mother's reproductive history, and intervals between births are readily computed. First-born children have no previous interval. The interval from marriage to first birth is a biologically distinct event relative to other intervals. It has been previously described (Stevenson et al. 1994) but will be discussed here relative to women with and without deaths. Multiple births are given the averaged rank order of their birth; for example, twins born as the first and second children are each given the birth order of 1.5. Births associated through multiple marriages, presumably through widowhood, are also eliminated from the sample. Households were reconstituted after the death of a parent, and women with a second husband are not biologically comparable to women who bear all their children to one person. These second marriages are also difficult to reconstruct. Thus all births in this analysis reflect married-only-once couples and include mothers born before 1850 in Prussia and Russia and those born after 1850 in Kansas.

Prussia and Russia are lumped together to increase sample sizes and because Prussia and Russia had harsher ecologies relative to 19th-century Kansas. They also provide a contrast in factors beyond a parent's control, Pennington and Harpending's "care-independent factors." In Prussia and Russia humans died from cholera (epidemic in the 1850s), diphtheria, measles, smallpox, typhus, 
whooping cough, and miscellaneous fevers (Everson et al. 1995; Toews 1986). Survivorship for males at 5 years is about 48 years in Prussia and 45 years in Russia and averages about 57 years after the move to Kansas (Stevenson and Everson 2000). Survivorship for females at age 5 years is 49 years in Prussia, is about the same in Russia at 50 years, and then somewhat improves in Kansas at 53 years.

First, the relationship between reproductive success (survivorship to 15 years) and completed family size was determined by calculating both linear and quadratic regressions (using SPSS 11.0) for mothers of this Mennonite congregation to see whether there is an optimum family size. Variation within these Mennonite families may obscure evidence for optimality. Thus these analyses were made for the total sample, for subsamples representing two disease settings, for Prussia/Russia (women born before 1850), and for Kansas (women born after 1850 ). Within those groupings, analyses were also made for all families with deaths versus those with no deaths (Prussia/Russia plus Kansas), and for subsamples of families with and without deaths representing Prussia/Russia versus Kansas. Variation within these groups was also examined by calculating measures of reproductive success (average and median number of live births versus average and median numbers of children who survived to 15 years of age), average and median ages at marriage, and birth span (the span between average ages of first and last births). $t$ tests with Bonferroni correction were used for pairs of comparisons: total Prussia/Russia vs. total Kansas, total mothers with deaths vs. total mothers without deaths, Prussian/Russian mothers with deaths vs. Prussian/Russian mothers without deaths, and Kansan mothers with deaths vs. Kansan mothers without deaths.

In addition, Cox regression hazards analyses were performed to better understand the interrelationships between offspring survivorship to 15 years versus covariates for the total sample and also the total subdivided by mothers born before 1855 (Prussia/Russia) versus mothers born in or after 1855 (Kansas). The Cox regression tests the null hypothesis that the lengths of the birth intervals, mother's age at the birth of index child, and the values of the other covariates have no effect on mortality and also accounts for censored observations, that is, events that occur within a specified time. In this analysis, censored cases are all deaths that occur before reaching 15 years of age, and the dependent variable is the cumulative survival function, the proportion of cases in which the event of interest has not yet occurred given some time period (Norusis 1994). The cumulative survival function represents the proportion of children who survive to a given age. The covariates can be either continuous or categorical variables. The $B$ coefficients express the amount of change in the baseline survival function brought about by a unit change in the independent variables. Positive coefficients lead to decreased survivorship, and negative coefficients lead to increased survivorship.

The variables used in the Cox regression analyses are defined in the following list. The first category of binary variables was coded as 0 . 
Child's birth order: $1-6$ birth order vs. $7+$ birth order.

Child's sex: female vs. male.

Death in sib set: no deaths in the sib set vs. at least one death in the sib set. Mother migrates: children all born in one locale vs. children born in two locales; dislocation's impact; for Prussia/Russia the migration from Prussia to Russia, and for Kansas the Russia to Kansas migration; for total sample, both migrations.

Mother's age at birth: younger than 35 vs. $35+$ years of age; used to assess whether there is increased risk to children born to older rather than younger mothers.

Mother's age at death: survived to age 45 years vs. died before age 45 years; mothers who survived the entire reproductive span vs. those who did not.

Mother's birth cohort: women born before 1855 in Prussia/Russia vs. those born in 1855 or later and thus giving birth in Kansas.

Mother's parity: 6 or fewer births vs. 7 or more total births.

Multiple birth: single births vs. twin births (controls for the high level of twinning in this sample).

Previous interbirth interval: defined continuously in years between the preceding birth and the birth of the index child.

Prior sib survival: survived until birth of index child vs. died before birth of index child.

\section{Results}

Included in the analyses are 1,026 and 1,324 births by $159(40.2 \%)$ and 237 (59.8\%) mothers from Prussia/Russia and Kansas, respectively, for a total of 2,350 children by 396 once-married mothers. Fifty-two percent of these mothers, $56 \%$ of Prussian/Russian mothers, and $49 \%$ of Kansan mothers experienced the death of at least one child. There were $22.47 \%$ and $29.55 \%$ of Prussian/Russian and Kansan families with deaths, respectively, and $17.68 \%$ and $30.30 \%$ Prussian/ Russian and Kansan families without deaths. The proportions of children surviving to age 15 years for the total sample of families is $84 \%$, for Prussian/Russian families $80 \%$, for Kansan families $86 \%$, for all sib sets with deaths $69 \%$, for Prussian/Russian sib sets with deaths $65 \%$, and for Kansan sib sets with deaths $73 \%$.

The $r$ and $r^{2}$ values for all pairs of quadratic and linear regressions are presented in Table 1 . None of the quadratic and linear regressions were significantly different for their $r$ values or their percentages of variance $\left(r^{2}\right)$ explained. All pairs of regressions performed equally well, which is illustrated in graph form in Figures 1, 2, and 3. The $r$ values ranged from 0.832 for families with deaths in Prussia/Russia to 0.929 for all families from Kansas. Likewise, $r^{2}$ values ranged from 0.685 for families with deaths in Prussia/Russia to 0.863 for all families from Kansas. 


\section{4 / STEVENSON ET AL.}

Table 1. Regression Results: Proportion of Variance Explained for Total, Locale, Sib Set Mortality, and Locale by Sib Set Mortality Data Sets

\begin{tabular}{lcc} 
Data Set & Linear & Quadratic \\
\hline Total & & \\
$\quad r$ (multiple $r$ ) & 0.885 & 0.888 \\
$\quad r^{2}$ & 0.783 & 0.787 \\
Prussia/Russia & & \\
$\quad r$ (multiple $r$ ) & 0.840 & 0.841 \\
$\quad r^{2}$ & 0.704 & 0.704 \\
Kansas & & \\
$\quad r$ (multiple $r$ ) & 0.927 & 0.929 \\
$r^{2}$ & 0.858 & 0.863 \\
Sib sets with deaths & & \\
$\quad r$ (multiple $r$ ) & 0.870 & 0.872 \\
$r^{2}$ & 0.756 & 0.757 \\
Prussian/Russian sib sets with deaths & & \\
$\quad r$ (multiple $r$ ) & 0.832 & 0.832 \\
$r^{2}$ & 0.688 & 0.685 \\
Kansan sib sets with deaths & & \\
$r$ (multiple $r$ ) & 0.923 & 0.926 \\
$r^{2}$ & 0.850 & 0.856 \\
\hline
\end{tabular}

Table 2 presents reproductive measures, including average (and median) number of children born versus surviving children, measures related to reproductive span, and average interbirth intervals. Children born ( $\mu \pm \mathrm{SE})$ ranged from $4.1 \pm 0.221$ children for Kansas mothers with no deaths to $8 \pm 0.338$ children for Prussian/Russian mothers with deaths. There were significantly more children born for total Prussia/Russia vs. total Kansas, for total sib sets with deaths vs. total sib sets with no deaths, for Prussian/Russian sib sets with deaths vs. Prussian/Russian sib sets with no deaths, and for Kansan sib sets with deaths vs. Kansan sib sets with no deaths. Reproductive success, the number of children alive at age 15 years, ranged from $4.1 \pm 0.221$ for Kansan mothers with no deaths to $5.4 \pm 0.185,0.294$, and 0.239 , for total sib sets with deaths, Prussian/ Russian sib sets with deaths, and Kansas sib sets with deaths, respectively. Significantly more children survived to age 15 years for total sib sets with no deaths vs. total sib sets with deaths (69\% more) and for Kansan sib sets with no deaths vs. Kansan sib sets with deaths ( $73 \%$ more).

The average ages at marriage range from $21.6 \pm 0.398$ years for Prussian/ Russian sib sets with deaths to $23.2 \pm 0.386$ years for Kansan sib sets with no deaths. There were significant differences in ages at marriage between Prussian/ Russian sib sets and Kansan sib sets (older) and between total sib sets with no deaths and total sib sets with deaths (younger).

The average ages of mothers at birth of first child, range from $21.2 \pm 0.433$ years for Prussian/Russian mothers with deaths to $24.5 \pm 0.444$ years for Kansan mothers with no deaths. Average ages at first birth were significantly different for total Prussian/Russian sib sets vs. Kansan sib sets (older), total sib sets with 

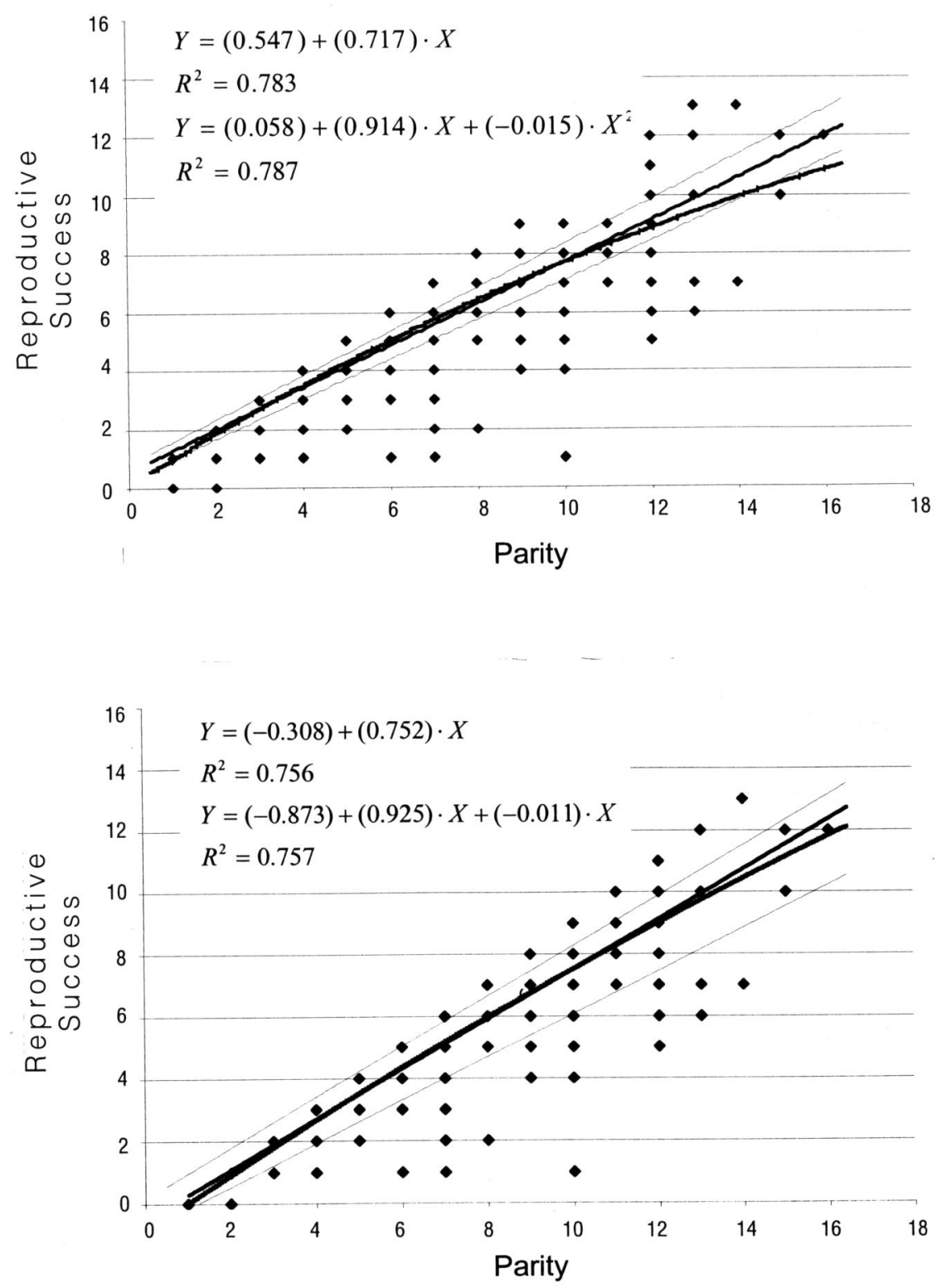

Figure 1. Reproductive success vs. parity: (top) total sib sets; (bottom) sib sets with deaths. 
676 / STEVENSON ET AL.
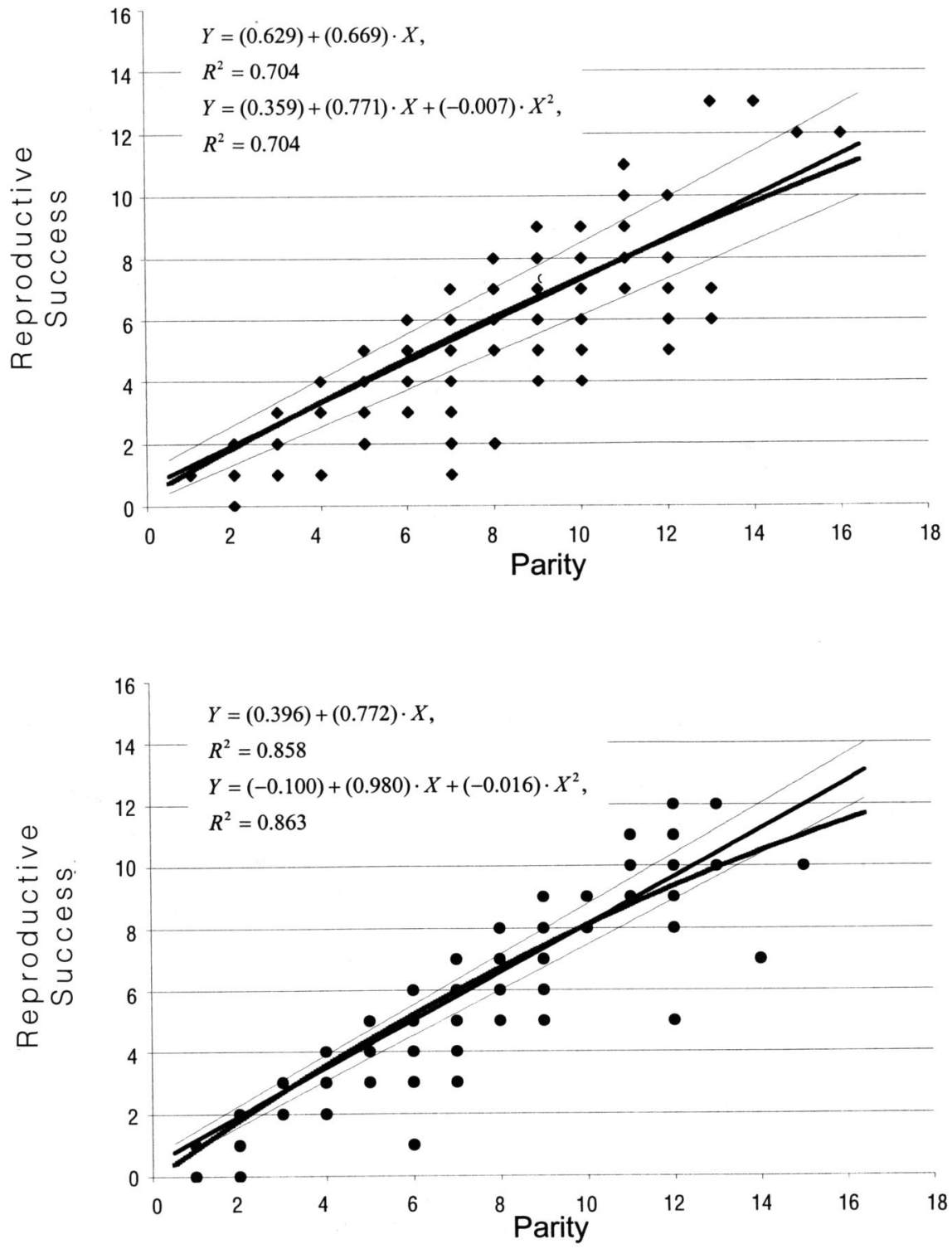

Figure 2. Reproductive success vs. parity: (top) total Prussian/Russian sib sets; (bottom) total Kansas sib sets. 

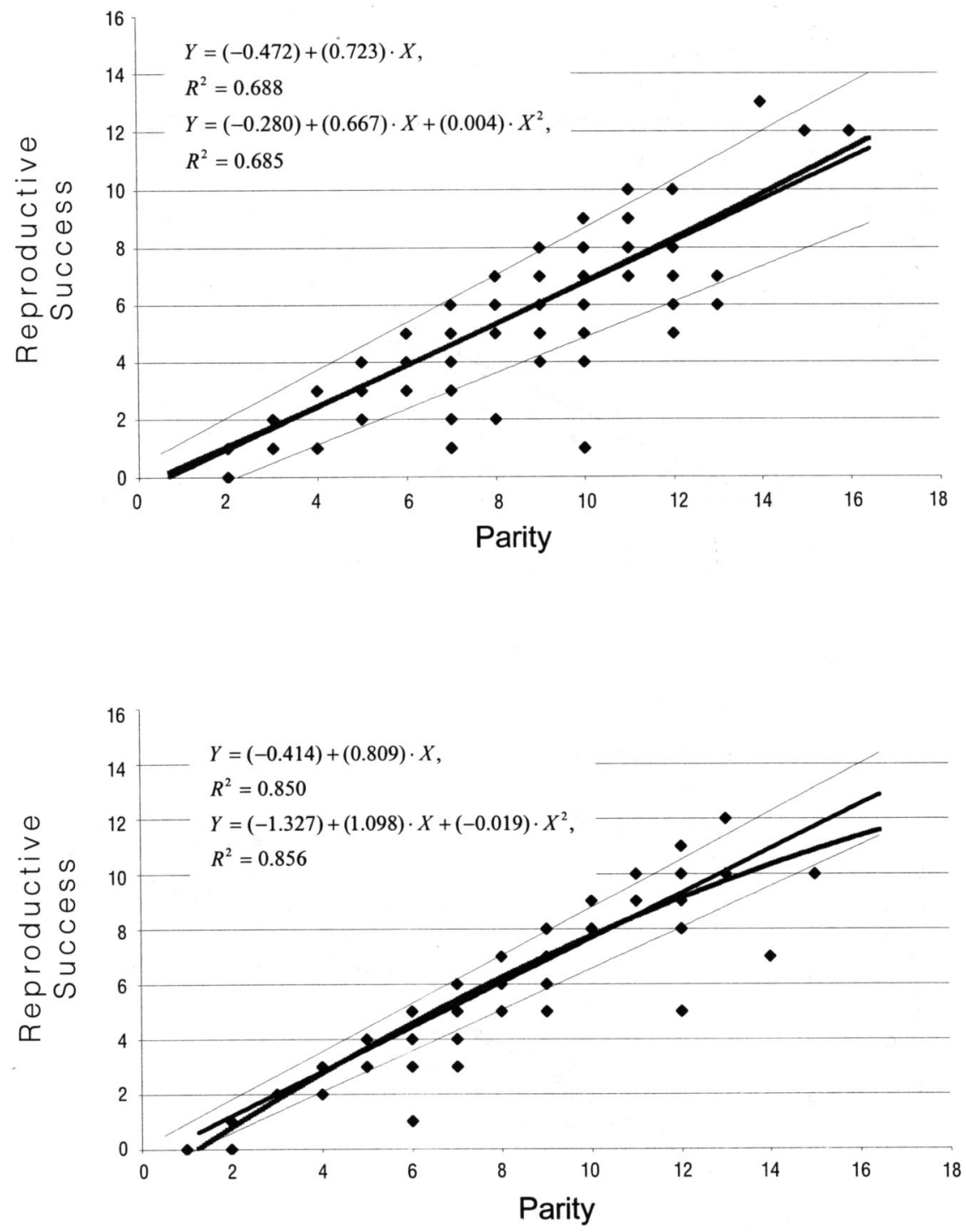

Figure 3. Reproductive success vs. parity: (top) Prussian/Russian sib sets with deaths; (bottom) Kansas sib sets with deaths.

no deaths vs. total sib sets with deaths (younger), Prussian/Russian sib sets with no deaths vs. Prussian/Russian sib sets with deaths (younger), and Kansan sib sets without deaths vs. Kansan sib sets with deaths (younger). The average ages of mothers at birth of last child ranged from $32.5 \pm 0.509$ years for Kansan sib sets with no deaths to $35.5 \pm 0.432$ years for Kansan sib sets with deaths. Significant differences are evident for total sib sets with no deaths vs. total sib sets 
678 / STEVENSON ET AL.

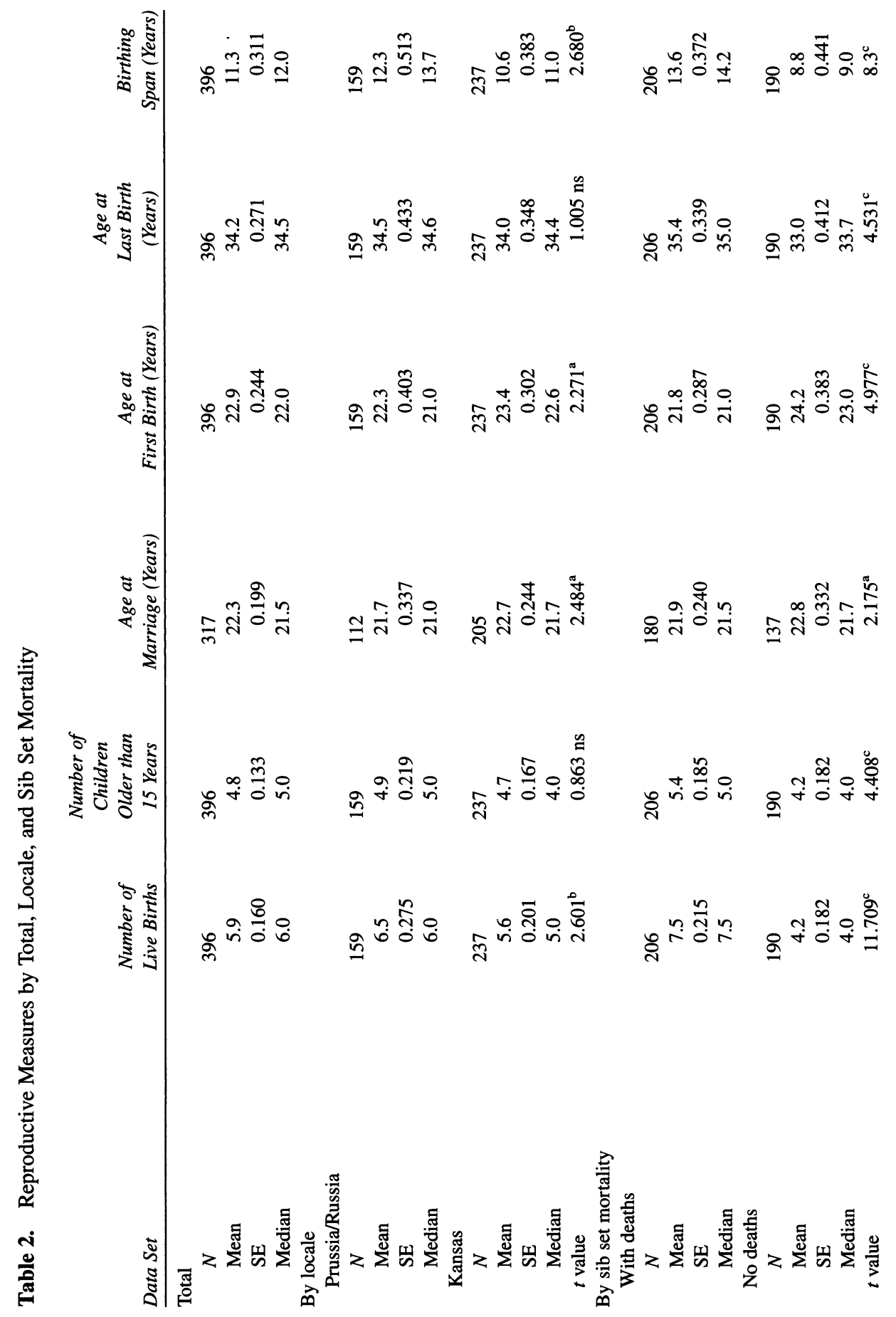




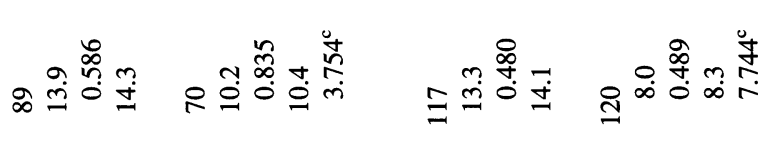

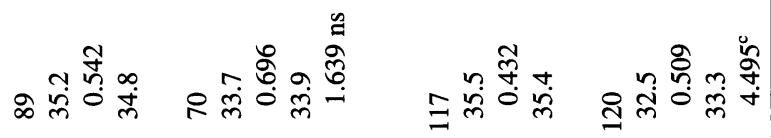

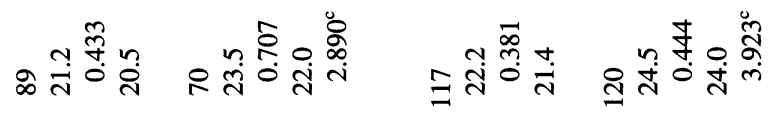

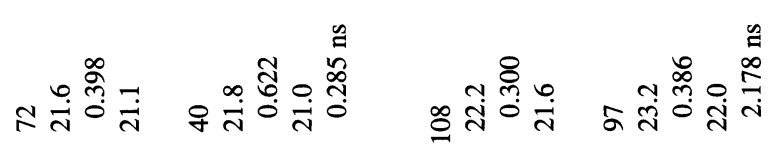

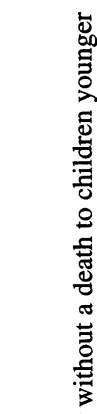

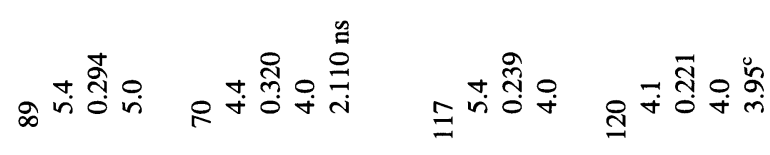

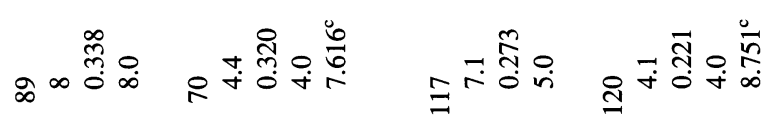

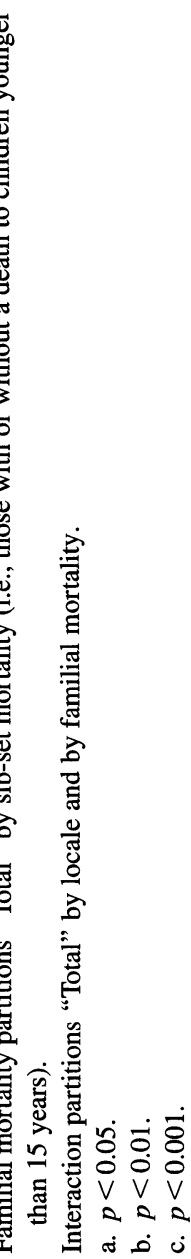


Table 3. Cox Regression Coefficients and Significance by Total and by Locale

\begin{tabular}{lccc} 
Covariate & Total B & Prussia/Russia B & Kansas B \\
\hline Child's birth order [(<6), $(7+)]$ & 0.192 & 0.053 & 0.299 \\
Child's sex [(female), (male)] & 0.189 & 0.253 & 0.161 \\
Death in sib set [(none), $(1+)]$ & $-1.782^{\mathrm{c}}$ & $-2.215^{\mathrm{c}}$ & $-1.565^{\mathrm{c}}$ \\
Mother's age at birth [(<35), $(35+)]$ & -0.288 & -0.272 & -0.384 \\
Mother's age at death [(<45), (45+)] & -0.008 & 0.080 & -0.086 \\
Mother's birth cohort [(Prussia/Russia), (Kansas)] & 0.207 & - & - \\
Mother migrates [(no), (yes)] & $-0.306^{\mathrm{a}}$ & $-0.403^{\mathrm{a}}$ & -0.196 \\
Mother's parity [(<6), $(6+)]$ & 0.168 & 0.046 & 0.220 \\
Multiple birth [(single), (twins +$)]$ & $-0.511^{\mathrm{a}}$ & -0.554 & -0.468 \\
Previous interbirth interval (years) & $-0.017^{\mathrm{b}}$ & $-0.018^{\mathrm{a}}$ & $-0.015^{\mathrm{a}}$ \\
Prior sib survival [(live), (die)] & -0.248 & -0.364 & -0.138 \\
Overall $\chi^{2}$ & 148.746 & 69.14 & 54.216 \\
df & 11 & 10 & 10 \\
Significance & 0.000 & 0.000 & 0.000
\end{tabular}

a. $P<0.05$

b. $P<0.01$.

c. $P<0.001$.

with deaths (older) and for Kansan sib sets with no deaths vs. Kansas sib sets with deaths (older).

The nearly identical numbers for average (or median) age at first marriage and first birth reflect the fact that there are a number of women marrying in their late 30s and early 40s for the first time and very few getting married in their teens. In addition, these women get pregnant soon after marriage.

Reproductive or birthing span, the interval between first and last births, ranged from $8 \pm 0.489$ years for Kansan sib sets without deaths to $13.9 \pm 0.586$ years for Prussian/Russian sib sets with deaths. There were significant differences in all comparisons of reproductive spans: between total sib sets with no deaths and total sib sets with deaths (longer), between total Prussian/Russian sib sets (longer) and total Kansas sib sets, between Prussian/Russian sib sets with no deaths and Prussian/Russian sib sets with deaths (longer), and between Kansan sib sets with no deaths and Kansan sib sets with deaths (longer).

Table 3 presents the $B$ coefficient for each covariate relative to survivorship to 15 years for the total sample and for the sample subdivided into Prussia/Russia and Kansas. For the total sample survivorship to 15 years is significantly increased if there is no death in the sib set, if the prior interbirth interval is longer, if the mother does not migrate, and if the proband is not a member of a twin pair. In Prussia/Russia survivorship is increased if there is no death in the sib set, if prior interbirth intervals are longer, and if the mother does not migrate. In Kansas survivorship is significantly increased if there is no death in the sib set and if the previous interbirth interval is longer.

\section{Discussion}

The regressions described in Figures 1, 2, and 3 and in Table 1 demonstrate that the more children women bear, the higher the reproductive success, whether 
the women experience children's deaths or not. There is variation in this group, especially between sib sets with deaths and sib sets without deaths, but the essentially linear relationship between number of children born and increasing reproductive success holds true. As apparent in Table 2, the women having more children may lose proportionately more children, but they have on average a larger completed family size relative to families losing no children.

The logistic regressions in Table 3 provide support for this picture. Survivorship is significantly increased for total, Prussia/Russia, and Kansas given no deaths in the family and longer previous interbirth intervals. Being a member of a twin pair is also a disadvantage, and migrating during births is a problem for the total sample and for the migration from Prussia to Russia, which from historical accounts was a more challenging move (Rempel 1974; Urry 1989). There were more local Mennonites willing to provide temporary accommodations and resources after the move to Kansas.

St. George et al.'s (2000) analysis, drawing from the same data as this study, provides an interesting contrast. The objectives of their analysis were different, and they examined survivorship for younger age categories. The goal was to determine the significance of maternal depletion versus sibling competition for three age groups [neonate (birth to 1 month), post-neonate (1 month to 1 year), and early childhood (1-5 years)] given a similar but not identical set of covariates: birth order $(<8$ vs. $8+)$, maternal mortality or age at death $(<45$ vs. $45+)$, mother's age at birth ( $<35$ vs. $35+)$, multiple birth (single vs. twins), parity $(<8$ vs. $8+$ ), prior sib survival (live vs. die), previous interval (in months), and subsequent interval (in months). Survivorship decreased for neonates and postneonates in Prussia/Russia because of having mothers older than 35 years and having shorter subsequent intervals; for early childhood survivorship decreased because of shorter previous and subsequent intervals. In Kansas survivorship decreased for neonates because of shorter subsequent intervals and being a member of a multiple birth for neonates; for post-neonates because of shorter previous and subsequent intervals and for being member of a multiple birth for postneonates; and for early childhood because of being a member of a multiple birth, for being preceded by a dead child, and for shorter subsequent intervals. The increased risk in Prussia/Russia associated with being born to an older mother and shorter previous interbirth intervals provides some support for the impact of maternal depletion, and the importance of longer subsequent intervals provides limited support for the sibling competition hypothesis.

Also presented by St. George et al. (2000) are figures presenting mortality rates by interbirth intervals for the three younger age groups. The high mortality among index children with short previous intervals declines rapidly as interval length increases and levels off for intervals greater than about 2 years (21.5-27.5 months). This suggests an "optimal" interbirth threshold, depending on context, as predicted by Pennington and Harpending (1988). For example, demographers may not be looking for optimizing behaviors relative to maximization of fitness (and family size), but many are interested in optimal interbirth intervals that minimize mortality (surely a reasonable proxy for fitness) and there is much 
evidence for threshold effects. Stevenson (1923) was one of the first to examine child-spacing effects on child mortality using a 1911 population census of England and Wales. He suggested that an optimal average birth interval for child survivorship is between 2.5 and 3 years. In the same year Hughes noted that infant mortality increased substantially for previous intervals less than 15 months for second and higher order births in a sample from Gary, Indiana.

Additional studies have confirmed and clarified these relationships, but only a sample will be reviewed briefly here. Cleland and Sathar (1984) noted that birth intervals less than 2 years are particularly apt to increase the risk of mortality, especially for Pakistani neonates, although even that risk of mortality declines steeply if intervals increase to at least to 30-35 months. There was no apparent threshold for later ages. Hobcraft et al. $(1983,1985)$ demonstrated in World Fertility Survey samples representing 27 and 35 countries, respectively, that close subsequent births raised the risk of mortality for the index child and that children born less than 2 years after the last child were significantly more likely to die within the first 5 years of life, especially when the previous child had died. They found little effect from high birth order or high ages of mother at birth. The excess risk associated with a child born 2-4 years before the index child had died suggested family factors might increase risk. Palloni and Millman (1986) also examined World Fertility Survey data from 12 Latin American countries and found that birth intervals longer than 36 months resulted in significant reductions in mortality, particularly in countries with high mortality. However, in locations with more resources interbirth intervals still matter. For example, Smith et al. (2003) found that children conceived within 6 months of the last birth exhibit a threefold increase in risk of neonatal death compared to children conceived between 18 and 24 months in 19th- and early 20th century Holland.

Interbirth intervals are more important than birth order in many instances and are still important after controlling for breast feeding. Mturi and Curtis (1995) found that Tanzanian children born after intervals of less than 2 years have an increased risk of neonatal death compared to children with longer intervals, independent of birth order, although excess risk does occur for births of order 5 or more. However, there is little evidence of increased mortality risk for children born after 24-35 months versus intervals of 36 or more months. Manda (1999) examined childhood mortality in Malawi and noted that mortality risk is increased substantially in first and higher order births, in birth intervals 18 months or less in length, and in younger and older mothers. Breast-feeding differences explain some of the differences for all the variables, except for preceding birth interval and birth order, although preceding birth interval is more important than birth order. Nath et al. (1994) also found that breast-feeding duration was important for early childhood mortality, but when its effects are removed, children born to mothers after less than 15 months are still more likely to die in early childhood. Mortality in the first 2 years of life declined $25 \%$ between preceding birth intervals of 15-27 months and 72\% after birth intervals longer than 27 months. Forste (1994) also found that birth order was not as important as birth 
spacing and lactation for reducing infant and child mortality in Bolivia. Short preceding and succeeding intervals increased risk of death in the first 2 years of life.

Thus, to summarize, a brief review of the birth interval literature indicates that birth spacing has a significant impact on the risk of mortality, independent of many other factors, including breast feeding, although thresholds may vary depending on local ecology and family setting. There is only weak or mixed support for mother's age and higher birth order's effect on survivorship, also not supported in these data for survivorship to age 15 years, but previous interbirth interval length is still a significant factor in surviving to 15 years. Reduced caloric and micronutrient reserves are likely partial explanations for increased risk of death associated with short interbirth intervals (Smits and Essed 2001; Smits 2003). Short previous interbirth intervals are also associated with an increased risk of mortality resulting from congenital abnormalities and intrauterine growth retardation. There may also be an increased risk for reproductive abnormalities in the index child after short previous intervals (Smits et al. 1997, 2000). Thus the effects of short interbirth intervals may be longstanding in affected children (Lummaa 2003).

Another timing issue is that of reproductive span, which varies when measured as birthing span in this study. This Mennonite population marries relatively late because of the expectation that marriage-age adults be baptized and full members of the congregation (Stevenson et al. 1994). Consistent with this is that age-specific marital fertility rates are highest for ages 25-29 years (except during 1850-1874), and very few babies are born to teenage women. Thus, in general, the women's sexually active years (which can result in pregnancy) are relatively short. The mean age at marriage and birthing span are significantly older for total Kansan sib sets than for Prussian/Russian sib sets. However, there are additional significant differences in measures of birthing span between sib sets with deaths vs. sib sets with no deaths. Thus mothers of sib sets with deaths bear more children and, despite higher death rates, achieve more surviving children over a significantly longer interval between first and last births. In Prussia/Russia there are significantly more children born to mothers with deaths over longer reproductive and birthing spans and a significantly earlier age at first birth. All reproductive measures in Kansan sib sets (except age at last birth) are significantly different from Prussian/Russian sib sets, again associated with sib sets with deaths bearing more children, with having more children alive at age 15 years, and with longer reproductive spans reflecting an earlier start at childbearing and a later finish.

Mothers losing children are having a few more children over slightly longer reproductive and birthing spans, and the women having the most children also finish with the largest completed family size. Families with deaths are compensating for losses. The most significant covariate associated with a reduced survivorship to age 15 years in the logistic regression analyses was whether there was a death in the family. As a family variable it could possibly reflect reduced resources for mothers leading to maternal depletion and poorer outcomes for those children. 


\section{4 / STEVENSON ET AL.}

The duration of postpartum amenorrhea varies with the duration of breast feeding and also with the nutritional status of the mother (Tracer 1991, 1996; Vitzthum 1994). We have no information on breast feeding in this historical population, but whether or not mothers breast-fed, nutritional status would have had an impact on how soon the mother started cycling again. Plus, this was a society in which there were disparities in wealth and socioeconomic status, which also can have a large effect on body composition. Women likely varied in the amount of physical labor they experienced. Poorer women often worked as servants for wealthier women (Urry 1989). Maternal age and energetic factors coupled with breast feeding also affect postpartum ovarian function (Ellison et al. 1993; Ellison 2003).

In our case, lack of resources and poor maternal nutrition may be acting to shorten interbirth intervals by leading to the early cessation of breast feeding. This can be brought about by the death of a suckling infant, sickness of mother or child, or early weaning resulting from economic or other social pressures on the mother. Given the assumptions that families with infant deaths are lacking in resources and that the mothers are of poorer nutritional status, a reduction in breast feeding would lead to shorter interbirth intervals and higher fertility.

By the 20th century these Mennonites were experiencing demographic transition and were stopping having children sooner (Stevenson and Everson 1990). These rural farmers represent 19th-century Eastern Europe and late 19th and early 20th century America, which was a period of dramatic population increase in Western Europe (Molnar and Molnar 2000). Mortality declined, and many more children survived until adulthood. There were adjustment problems with each migration, particularly from Prussia to Russia, but in both cases, these farmers eventually thrived and out-competed their local neighbors (Rempel 1974; Urry 1989). Thus we suspect that nutrition for most mothers was adequate. Even mothers who lost children likely returned to cycling relatively fast [maybe not as fast as the wealthier women given roughly similar patterns of breast feeding (Ellison et al. 1993; Ellison 2003; Tracer 1991, 1996)] and bore more children. Even the families with losses increased their reproductive success the more children they had. Thus this migrating church congregation includes women making different choices under different circumstances, but in general, most interbirth intervals are likely above a minimum threshold and most children (and mothers) likely received adequate nutrition. Under these circumstances there is no point optimum for reproductive success, and presumably this led to population increases even before there were significant impacts from medical advances in 19th-century Europe and America (McKeown 1979). Perhaps an optimum for a specific family size relative to number of births, as evident in the work of Strassmann and Gillespie (2001), is more likely in environments that are consistently stressful (and energetically more taxing) for long periods of time, such as most contexts during much of the Pleistocene or in settings where food shortages are more consistent as a result of an exploitative ruling class. 


\section{Conclusions}

Linear and quadratic regressions demonstrate equally well that the more children born, the more children survive to age 15 years in this reproducing subsample representing married-only-once couples of migrating Mennonite families in two disease settings: more hostile Prussian and Russian rural settings and a friendlier rural Kansas, whether families experience deaths or not. However, these regressions do mask differences in reproductive patterns. Prussian/Russian mothers bore significantly more children than Kansan mothers over a longer reproductive span but did not significantly increase the number of children surviving to age 15 years. However, families experiencing deaths exhibited significantly longer reproductive spans, reflecting a significantly earlier start in childbearing and a later finish, and also produced significantly more children significantly closer together. The significantly longer spans between first and last births for mothers of sib sets with deaths and mothers of sib sets without deaths is also apparent within the samples of Prussian/Russian and Kansan families.

Survivorship as measured by logistic regressions increases for total, Prussia/Russia, and Kansas, given no deaths in the family and longer previous interbirth intervals. We postulate that a linear relationship between children born and surviving children at age 15 years reflects a threshold effect in interbirth intervals (rather than a point optimum) and, likely, adequate nutrition.

Acknowledgments We thank the members of the Alexanderwohl congregation and Michael Crawford and Laurine Rogers for access to these data.

Received 29 September 2003; revision received 3 March 2004.

\section{Literature Cited}

Blurton Jones, N.G. 1997. Too good to be true? Is there really a trade-off between number and care of offspring in human reproduction? In Human Nature: A Critical Reader, L. Betzig, ed. New York: Oxford University Press, 83-86.

Blurton Jones, N.G., and R.M. Sibly. 1978. Testing adaptiveness of culturally determined behaviour: Do Bushman women maximize their reproductive success by spacing births widely and foraging seldom? In Human Behaviour and Adaptation, N.G. Blurton Jones and V. Reynolds, eds. Society for Study of Human Biology Symposium 18. London: Taylor \& Francis, 135-158.

Cleland, J.G., and Z.A. Sathar. 1984. The effect of birth spacing on childhood mortality in Pakistan. Popul. Stud. 38:401-418.

Duerksen, J.A. 1955. Przechowka and Alexanderwohl: Beginnings of Alexanderwohl, Tabor, Huffnungsau, and other churches. Mennonite Life 10:76-82.

Ellison, P.T. 2003. Energetics and reproductive effort. Am. J. Hum. Biol. 15:342-351.

Ellison, P.T., C. Panter-Brick, S.F. Lipson et al. 1993. The ecological context of ovarian function. Hum. Reprod. 8:2,248-2,258.

Ens, A. 1989. Mennonite education in Russia. In Mennonites in Russia, 1788-1988: Essays in Honour of Gerhard Lohrenz, J. Friesen, ed. Winnipeg, Canada: CMBC Publications, 75-97. 


\section{6 / STEVENSON ET AL.}

Everson, P.M., J.C. Stevenson, and L. Rogers. 1995. Mortality in a migrating Mennonite church congregation. Hum. Biol. 67:69-86.

Forste, R. 1994. The effects of breastfeeding and birth spacing on infant and child mortality in Bolivia. Popul. Stud. 48:497-511.

Haury, D.A. 1981. Prairie People: A History of the Western District Conference. Newton, KS: Faith and Life Press.

Hobcraft, J., J.W. McDonald, and S. Rutstein. 1983. Child-spacing effects on infant and early child mortality. Popul. Index 49:585-618.

Hobcraft, J., J.W. McDonald, and S. Rutstein. 1985. Demographic determinants of infant and early child mortality: A comparative analysis. Popul. Stud. 39:363-385.

Hughes, E. 1923. Infant mortality: Results of a Field Study in Gary, Indiana, Based on Births in One Year. Children's Bureau Publication 112. Washington, DC: U.S. Government Printing Office.

Lack, D. 1947. The significance of clutch size. Ibis 89:302-352.

Lummaa, V. 2003. Early developmental conditions and reproductive success in humans: Downstream effects of prenatal famine, birthweight, and timing of birth. Am. J. Hum. Biol. 15:370-379.

Luttbeg, B., and R.R. Warner. 1999. Reproductive decision-making by female peacock wrasses: Flexible versus fixed behavioral rules in variable environments. Behav. Ecol. 10:666-674.

Manda, S.O.M. 1999. Birth intervals, breastfeeding, and determinants of childhood mortality in Malawi. Soc. Sci. Med. 48:301-312.

McKeown, T. 1979. The Role of Medicine: Dream, Mirage, or Nemesis? Princeton, NJ: Princeton University Press.

McNamara, J.M. 1998. Phenotypic plasticity in fluctuating environments: Consequences of the lack of individual optimization. Behav. Ecol. 9:642-648.

Mennonite Immigrant Historical Foundation. 1980. Church Records of the Old Flemish or Groningen Mennonisten Societaet in Przechowko, West Prussia, L. Pankratz and A.M. Unruh, trans. Goessel, KS: Mennonite Immigrant Historical Foundation.

Mennonite Immigrant Historical Foundation. 1987. Church Book of the Alexanderwohl Mennonite Church in the Molotschna Colony of South Russia, V.R. Duerksen and J.A. Duerksen, trans. Goessel, KS: Mennonite Immigrant Historical Foundation.

Miller, W.B. 1994. Reproductive decisions: How we make them and how they make us. Adv. Popul. 2:1-27.

Molnar, S., and I.M. Molnar. 2000. Environmental Change and Human Survival: Some Dimensions of Human Ecology. Upper Saddle River, NJ: Prentice Hall.

Mturi, A.J., and S.L. Curtis. 1995. The determinants of infant and child mortality in Tanzania. Health Policy Plann. 10:384-394.

Nath, D.C., K.C. Land, and K.K. Singh. 1994. Birth spacing, breastfeeding, and early child mortality in a traditional Indian society: A hazards model analysis. Soc. Biol. 41:168-180.

Norusis, M.J. 1994. SPSS Advanced Statistics, 6.1. Chicago: SPSS.

Palloni, A., and S. Millman. 1986. Effects of interbirth intervals and breastfeeding on infant and early childhood mortality. Popul. Stud. 40:215-236.

Pennington, R. 1992. Did food increase fertility? Evaluation of !Kung and Herero history. Hum. Biol. 64:497-521.

Pennington, R. 2001. Hunter-gatherer demography. In Hunter-Gatherers: An Interdisciplinary Perspective, C. Panter-Brick, R.H. Layton and P. Rowley-Conwy, eds. Cambridge: Cambridge University Press, 170-204.

Pennington, R., and H. Harpending. 1988. Fitness and fertility among Kalahari !Kung. Am. J. Phys. Anthropol. 77:303-319.

Pennington, R., and H. Harpending. 1993. The Structure of an African Pastoralist Community: Demography, History, and Ecology of the Ngamiland Herero. New York: Oxford University Press.

Rempel, D.G. 1974. The Mennonite commonwealth in Russia: A sketch of its founding and endurance, 1789-1919. Mennonite Q. Rev. 48:5-54. 
Smith, G.C.S., J.P. Pell, and R. Dobbie. 2003. Interpregnancy interval and risk of preterm birth and neonatal death: Retrospective cohort study. Br. Med. J. 327:313-318.

Smits, L. 2003. Letter to the editor: Interpregnancy intervals and reproductive success. Am. J. Hum. Biol. 16:96.

Smits, L.J.M., and G.G. Essed. 2001. Hypothesis: Short interpregnancy intervals and unfavourable pregnancy outcome - role of folate depletion. Lancet 358:2,074-2,077.

Smits, L.J., W.N.P. Willemsen, G. Zielhuis et al. 1997. Conditions at conception and risk of menstrual disorders. Epidemiology 8:524-529.

Smits, L.J., P.H. Jongbloet, and G.A. Zielhuis. 2000. Fecundity of daughters born after short, intermediate, or long birth intervals: An analysis of family reconstitutions from the Netherlands, 19th and early 20th century. Soc. Biol. 47:18-33.

Stevenson, J.C., and P.M. Everson. 1990. The cultural context of fertility transition in immigrant Mennonites. In Fertility and Resources, J. Landers and V. Reynolds, eds. Cambridge: Cambridge University Press, 47-61.

Stevenson, J.C., and P.M. Everson. 2000. Historical demography of Mennonite populations. In Different Seasons: Biological Aging Among the Mennonites of Midwestern United States, M.H. Crawford, ed. Publications in Anthropology 21. Lawrence, KS: Department of Anthropology, University of Kansas, 19-30.

Stevenson, J.C., P.M. Everson, and L. Rogers. 1994. Changes in fertility behavior relative to starting, stopping, and spacing behaviors in a migrating Mennonite community, 1775-1889. Soc. Biol. 41:83-95.

Stevenson, T.H.C. 1923. Fertility. In Census of England and Wales, 1911, v. 13, Fertility of Marriage, part II. London: HM Stationery Office.

St. George, D., P.M. Everson, J.C. Stevenson et al. 2000. Birth intervals and early childhood mortality in a migrating Mennonite community. Am. J. Hum. Biol. 12:50-63.

Strassmann, B.I., and B. Gillespie. 2001. Life-history theory, fertility, and reproductive success in humans. Proc. R. Soc. Lond. 269:553-562.

Toews, J.B. 1986. Childbirth, disease, and death among Mennonites in nineteenth-century Russia. Mennonite Q. Rev. 60:450-468.

Tracer, D.P. 1991. Fertility-related changes in maternal body composition among the Au of Papua New Guinea. Am. J. Phys. Anthropol. 85:393-405.

Tracer, D.P. 1996. Lactation, nutrition, and postpartum amenorrhea in lowland Papua New Guinea. Hum. Biol. 68:277-292.

Urry, J. 1989. None But the Saints: The Transformation of Mennonite Life in Russia-1789-1889. Winnipeg, Canada: Hyperion Press.

Vitzthum, V.J. 1994. Comparative study of breastfeeding structure and its relation to human reproductive ecology. Yrbk. Phys. Anthropol. 37:307-349. 